\title{
Effect of pre-pregnancy maternal body mass index on pregnancy outcomes in nulliparous women in the Islamic Republic of Iran
}

Marzieh Sfandiary ${ }^{1}$, Shamsi Parvizi ${ }^{1}$, Afshin Almasi ${ }^{2}$ and Frozan Sharifipour ${ }^{1}$

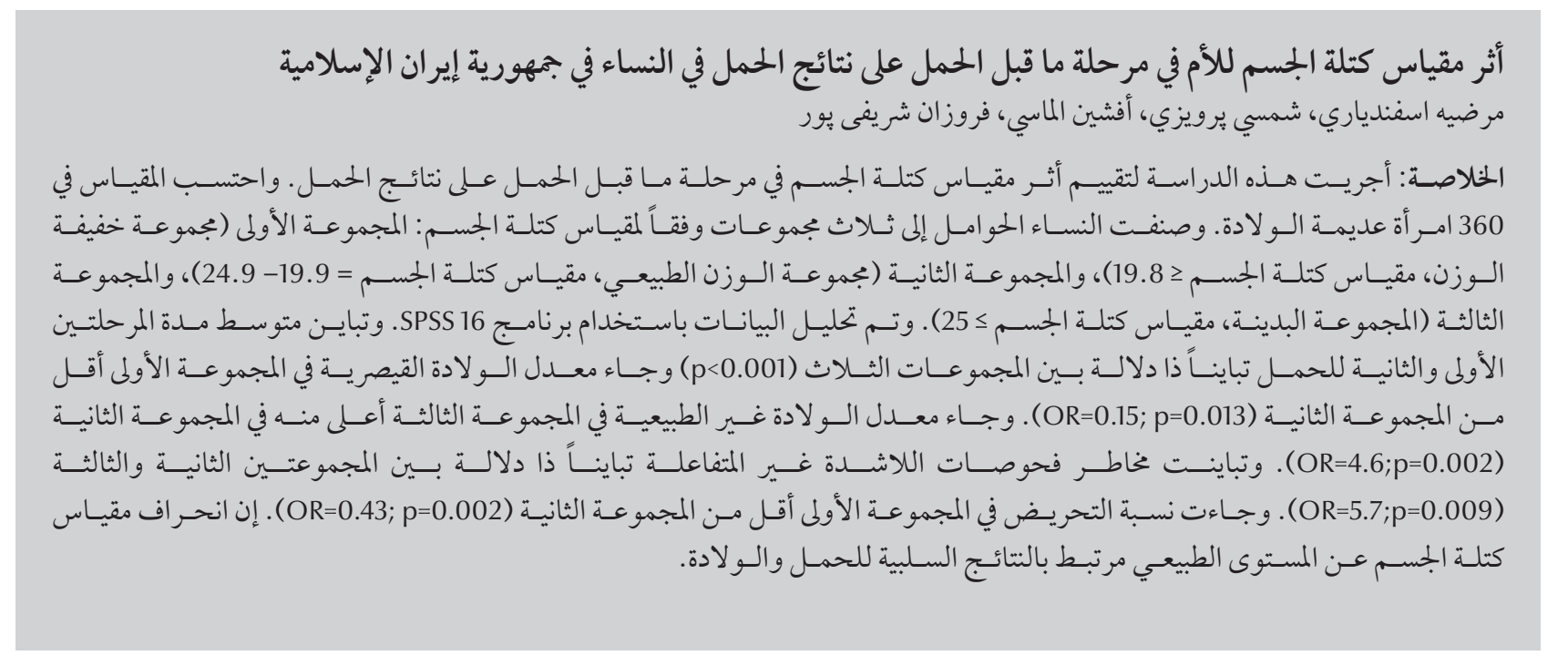

ABSTRACT This study was conducted to evaluate the effect of pre-pregnancy BMI on pregnancy outcomes. BMI was calculated measured in 360 nulliparous women. According to BMI, pregnant women were placed into three groups: group I (lean group BMI $\leq 19.8$ ), group II (normal weight group BMI $=19.9-24.9$ ), and group III (obese group $\mathrm{BMI} \geq 25$ ). Data were analyzed using SPSS 16 . The mean duration of the first and the second stage of labour were significantly different between three groups $(P<0.001)$. Cesarean section ratio in group I was lower than group II (OR $=0.15 ; P=0.013)$. Instrumental delivery in group III was more than group II ( $\mathrm{OR}=4.6 ; P=0.002)$. Risk of nonreactive non-stress test (NST) was significantly different between groups II and III (OR=5.7; $P=0.009$ ). Induction ratio in group I was lower than group II $(\mathrm{OR}=0.43 ; P=0.002)$. Deviation of $\mathrm{BMI}$ from the normal level is associated with adverse outcomes of pregnancy and delivery.

Impact de l'indice de masse corporelle maternel pré-gravidique sur les issues de grossesse parmi les femmes nullipares en République islamique d'Iran.

RÉSUMÉ La présente étude a été menée pour évaluer l'impact de l'IMC maternel pré-gravidique sur les issues de grossesse. L'IMC a été calculé pour 360 femmes nullipares. En fonction de l'IMC, les femmes enceintes ont été réparties en trois groupes: groupe I (poids maigre IMC $\leq 19,8$ ), groupe II (poids normal IMC = 19,924,9 ), et le groupe III (obésité IMC $\geq 25$ ). L'analyse des données a été réalisée à l'aide de la version 16.0 du logiciel SPSS. La durée moyenne des deux premières phases du travail était significativement différente entre ces trois groupes $(p<0,001)$. Le taux de césarienne dans le groupe I était inférieur à celui du groupe II $(\mathrm{OR}=$ $0,15 ; p=0,013)$. Le taux d'accouchement avec assistance instrumentale dans le groupe III était plus élevé que dans le groupe II (OR=4,6; $p=0,002)$. Le risque lié à l'absence ou la diminution des mouvements lors du test de réactivité foetale était significativement différent entre les groupes II et III (OR $=5,7 ; p=0,009)$. Le taux d'induction du travail dans le groupe I était inférieur à celui du groupe II (OR=0,4 $3 ; p=0,002)$. L'écart de l'IMC par rapport au poids normal est associé aux issues défavorables de la grossesse et de l'accouchement.

'Department of Midwifery, Nursing and Midwifery Faculty, Kermanshah University of Medical Sciences, Kermanshah, Islamic Republic of Iran (Correspondence to: Shamsi Parvizi: shamsiparvizik@gmail.com). ${ }^{2}$ Department of Biostatistics and Epidemiology, School of Health, Kermanshah University of Medical Sciences, Kermanshah, Islamic Republic of Iran.

Received: 29/01/16; accepted: 30/11/16 


\section{Introduction}

Improving maternal and fetal health is a key public health objective. In recent years, the body mass index (BMI) of women of reproductive age has risen in developed countries (1). Higher maternal BMI at the start of pregnancy or before pregnancy has been reported to increase physical and intellectual problems in neonates (e.g. cerebral palsy, hydrocephalus, seizures, vision, hearing and behavioural problems) (2).

Overweight and obese women are at increased risk of gestational diabetes, pre-eclampsia, instrumental delivery and caesarean section and their children are at higher risk of macrosomia, birth defects, low Apgar scores and neonatal complications $(1,3,4)$. Obese women have been reported to have longer labour due to insufficient contractions during the first stage of labour, therefore, the induction and augmentation rate is higher in this group. Obese women also have a longer second stage of labour, hence, they may need more stimulation by oxytocin. In addition, newborns of obese mothers have lower Apgar scores which increases the risk of fetal distress and prolonged hospitalization of the new born (2). The financial cost of the equipment used for caring for low-birthweight neonates as a result of preterm labour places a considerable burden on health services (3).

Most of these data are from studies conducted in developed countries. In developing countries, where poverty and malnutrition are higher, there is inadequate information about maternal BMI and its effects on pregnancy. Therefore, this study was conducted with the aim of evaluating the effect of BMI on pregnancy outcomes in nulliparous women in Kermanshah, Islamic Republic of Iran.

\section{Methods}

\section{Study design and setting}

We conducted a prospective study at Hazrat Masomeh Hospital in Kermanshah from October 2014 until September 2015. This is a general hospital affiliated to the Social Security Organization and has about 6000 births annually

\section{Study sample}

The sample was drawn from nulliparous women who intended to be pregnant and attended the hospital pregnancy clinic before pregnancy. Many women attend the clinic for routine preconception counselling.

BMI of the women was measured before pregnancy. Then in the first trimester, BMI was measured again. Women who were in the BMI group as before pregnancy and had a singleton pregnancy without any systemic disease, such as hypertension, diabetes and kidney disease that can affect pregnancy outcomes, were enrolled in the study and followed until delivery.

The sample size needed for the overweight/obese group was 130. Sampling was sequential until 130 obese/overweight women were found. Thus, 1000 nulliparous women who attended the clinic were assessed of which, 130 were overweight/obese. Then, 130 women each for the underweight and normal weight groups were randomly selected who were in the same BMI group before pregnancy and in the first trimester. In the overweight/obese group, 10 women left the study (did not deliver in the hospital), 8 women in the underweight group were omitted (6 did not consent to continue in the study and 2 did not deliver in the hospital) and 2 women in the normal weight group did not deliver in the hospital. Therefore, the final sample with the 3 groups was: 122 women in group I (thin group BMI $\leq 19.8 \mathrm{~kg} / \mathrm{m}^{2}$ ), 128 in group II (normal weight BMI $\left.=19.9-24.9 \mathrm{~kg} / \mathrm{m}^{2}\right)$ and 120 in group Ш (overweight/obese group BMI $\geq 25$ $\mathrm{kg} / \mathrm{m}^{2}$.

\section{Data collection}

Data were collected in a form designed by researchers. The form had two parts. The first part recorded demographic characteristics of the women: age, education, residence and BMI. The second recorded information about pregnancy outcomes: labour induction and augmentation, mode of delivery, duration of the first and second stages of labour (first stage: cervical dilation from 3-10 $\mathrm{cm}$; second stage: from full dilation until complete expulsion of the baby), neonate weight, history of mother's hospitalization during pregnancy, gestational age at delivery, gestational hypertension, fetal movement reduction and nonreactive non stress test.

\section{Ethical considerations}

Institutional review board approval was needed as this was not a clinical trial. All the women gave their consent to be included in the study.

\section{Statistical analysis}

Data were analysed using SPSS, version 16. Depending on the variable, chisquared, multinomial and binary logistic regression analyses were performed. $P<0.05$ was considered statistically significant.

\section{Results}

The sociodemographic characteristics of the women are shown in Table 1. Their mean age was 24.1 (SD 4.7) years, range $24.4-25.4$ years. The mean ages in groups $\mathrm{I}, \Pi$ and $\amalg$ were 24.6 (SD 4.5), 24.4 (SD 4.5) and 25.4 (SD 4.8) years respectively, with no statistically significant differences $(P>0.05)$. The majority of the women in all BMI groups were urban residents and were housewives. There was no significant difference between the groups with regard to residence (urban/rural) $(P=0.1)$ and employment status (employed/ unemployed $(P=0.3)$. Based on the chi-squared test, there was a significant 


\begin{tabular}{|c|c|c|c|c|}
\hline $\begin{array}{l}\text { Sociodemographic } \\
\text { characteristic }\end{array}$ & $\begin{array}{c}\text { Group I } \\
\text { BMI } \leq 19.8 \mathrm{~kg} / \mathrm{m}^{2} \\
(n=122)\end{array}$ & $\begin{array}{c}\text { Group II } \\
\text { BMI } 19.9-24.9 \mathrm{~kg} / \mathrm{m}^{2} \\
(n=128)\end{array}$ & $\begin{array}{c}\text { Group Ш } \\
\text { BMI } \geq 25 \mathrm{~kg} / \mathrm{m}^{2} \\
(n=120)\end{array}$ & $P$-value ${ }^{1}$ \\
\hline & No. (\%) & No. (\%) & No. (\%) & \\
\hline Education & & & & $<0.001$ \\
\hline Secondary & $60(49.2)$ & $51(39.8)$ & $43(35.8)$ & \\
\hline Diploma & $52(42.6)$ & 49 (38.3) & $53(44.2)$ & \\
\hline University & $10(8.2)$ & $28(21.9)$ & $24(20.0)$ & \\
\hline Residence & & & & 0.1 \\
\hline Urban & $87(71.3)$ & $101(78.9)$ & 99 (82.5) & \\
\hline Rural & $35(28.7)$ & 27 (21.1) & $21(17.5)$ & \\
\hline Employment & & & & 0.3 \\
\hline Employed & $4(3.3)$ & $4(3.1)$ & $8(6.7)$ & \\
\hline Unemployed & 118 (96.7) & 124 (96.9) & 112 (93.3) & \\
\hline
\end{tabular}

${ }^{1}$ Chi-squared test.

difference between BMI and level of education $(P<0.001)$ : $21.9 \%$ of women in Group II and $20.0 \%$ of women in Group III had a university degree compared with $8.2 \%$ in Group I.

Based on multinomial logistic regression, BMI did differ significantly with main outcomes: delivery mode $(P$ $=0.407)$, duration of the first and the second stages of labour $(P=0.579$ and $P=0.144$ respectively) and neonatal weight $(P=0.271)$.

Table 2 shows the obstetric characteristics of the nulliparous women by BMI. Maternal hospitalization history (e.g. for diabetes, urinary tract infections, hypertension and intrauterine growth restriction during pregnancy) was not significantly associated with BMI $(P=0.46)$. Among the 3 groups, 8 (6.6\%) women in group I, 10 (7.8\%) in group $\Pi$ and $13(10.8 \%)$ in group Ш had been hospitalized. With regard to gestational age, 10 women (8.2\%) in group I, 9 (7\%) in group $\Pi$ and 14 (11.7\%) in group Ш delivered pre-term (<38 weeks). Regarding fetal movement reduction during pregnancy and labour, 63 women (17\%) had fetal movement reduction during pregnancy: 28 in group $\Pi$ (21.9\%), 20 in group $\amalg(16.7 \%)$ and 15 in group I (12.3\%). However, based on chi-squared analysis the differences were not statistically significant $(P=0.13)$.

Table 3 shows the delivery characteristics and neonate weight among the nulliparous women by BMI. The mean duration of the first stage of labour was 196.8 (SD 113.1) minutes in group I, 231.7 (SD 99.4) minutes in group $\Pi$ and 267.1 (SD 112.6) minutes in group Ш.

The mean duration of the second stage of labour was 65.7 (SD 37.7) minutes in group Ш, 51.8 (SD 34.4) minutes in group $\Pi$ and 41 (SD 35.6) minutes in group I. The mean weight of the newborns delivered to the women was 3140.1 (SD 385.3) g in group I, 3246.8 (SD 449.01) $\mathrm{g}$ in group $\Pi$ and 3332.4 (SD 528.6) g in group Ш.

Table 4 shows the logistic regression analysis assessing the effect of BMI on pregnancy and obstetric outcomes. There was no significant difference in caesarean delivery compared with vaginal delivery between groups $\Pi$ and Ш (OR $=1.9 ; 95 \%$ CI: 0.94-4.16, P = 0.072 ); however, there was a significant difference between group I and group $\Pi(\mathrm{OR}=0.15$; 95\% CI: 0.03-0.68, P = $0.013)$. There were significantly more instrumental deliveries than vaginal deliveries in group $Ш$ compared with group $\Pi(\mathrm{OR}=4.6 ; 95 \%$ CI: $1.77-12.03, \mathrm{P}=$
$0.002)$, but not between groups I and $\Pi(\mathrm{OR}=2.4$ 95\% CI: 0.901-6.61, P = $0.078)$. There was no significant relationship between BMI and gestational age (term, preterm, post-term) in the 3 groups $(P=0.42)$.

According to the logistic regression results, the likelihood of gestational hypertension was significantly lower in group I than group $\Pi(\mathrm{OR}=0.01 ; 95 \%$ CI: $0.01-0.23, P=0.024)$, but there was no significant difference between groups $\amalg$ and $\Pi(\mathrm{OR}=0.96$; $95 \% \mathrm{CI}$ : $0.34-2.44, P=0.92)$. The likelihood of a nonreactive nonstress test was significantly higher in group III than group II (OR $=5.7 ; 95 \%$ CI: $1.40-17.06, P=0.009$ ), but there was no significant difference between groups II and I $(\mathrm{OR}=1.66$; 95\% CI: $0.412-6.69, P=0.47)$.

The likelihood of induction was not significantly different between groups $\Pi$ and $\amalg(\mathrm{OR}=1.4 ; 95 \% \mathrm{CI}: 0.82-2.45, P$ $=0.2$ ), but the likelihood induction was significantly lower in group I than group $\Pi(\mathrm{OR}=0.43$; 95\% CI: $0.26-0.73, P=$ 0.002 ). The likelihood of augmentation was not significantly different between groups $\Pi$ and $\amalg(\mathrm{OR}=1.6$; $95 \% \mathrm{CI}$ : $0.60-4.69, P=0.32)$ or groups I and $\Pi(\mathrm{OR}=0.5$; $95 \%$ CI: $0.16-1.54, P=$ $0.23)$. 


\begin{tabular}{|c|c|c|c|c|}
\hline Variable & $\begin{array}{c}\text { Group I: } \mathrm{BMI} \leq 19.8 \\
\mathrm{~kg} / \mathrm{m}^{2} \\
(n=122)\end{array}$ & $\begin{array}{c}\text { Group II: BMI } \\
\text { 19.9-24.9 kg/m² } \\
(n=128)\end{array}$ & $\begin{array}{c}\text { Group Ш: BMI } \geq 25 \\
\mathrm{~kg} / \mathrm{m}^{2} \\
(n=120)\end{array}$ & $P$-value \\
\hline & No. (\%) & No. (\%) & No. (\%) & \\
\hline Maternal hospitalization ${ }^{7}$ & & & & 0.46 \\
\hline Yes & $8(6.6)$ & $10(7.8)$ & $13(10.8)$ & \\
\hline No & $114(93.4)$ & $118(92.2)$ & $107(89.2)$ & \\
\hline Gestational hypertension & & & & 0.024 \\
\hline Yes & $1(0.8)$ & $10(7.8)$ & $9(7.5)$ & \\
\hline No & $121(99.2)$ & $118(92.2)$ & $111(92.5)$ & \\
\hline Fetal movement reduction & & & & 0.13 \\
\hline Yes & $20(16.4)$ & $28(21.9)$ & $20(16.7)$ & \\
\hline No & $102(83.6)$ & $100(78.1)$ & $100(83.3)$ & \\
\hline Nonreactive nonstress test $^{2}$ & & & & 0.032 \\
\hline Reactive (normal) & $11(68.8)$ & $22(78.6)$ & $9(42.9)$ & \\
\hline Non-reactive (abnormal) & $5(31.2)$ & $6(21.4)$ & $12(57.1)$ & \\
\hline Gestational age at delivery ${ }^{3}$ & & & & 0.416 \\
\hline Pre-term $(<38$ weeks $)$ & $10(8.2)$ & $9(7.0)$ & $14(11.7)$ & \\
\hline Term & $112(91.8)$ & 119 (93.0) & $106(88.3)$ & \\
\hline Post-term ( $\geq 42$ weeks) & $0(0)$ & $0(0)$ & $0(0)$ & \\
\hline Labour intervention & & & & $<0.001$ \\
\hline Induction & 45 (36.9) & $70(54.7)$ & $75(62.5)$ & \\
\hline Augmentation & $6(4.9)$ & $8(6.2)$ & $10(8.3)$ & \\
\hline None & $71(58.2)$ & $50(39.1)$ & $35(29.2)$ & \\
\hline Delivery mode $^{4}$ & & & & $<0.001$ \\
\hline Normal vaginal delivery & $103(86.6)$ & $108(84.4)$ & $78(66.1)$ & \\
\hline Caesarean section & $2(1.7)$ & $14(10.9)$ & $20(16.9)$ & \\
\hline Instrumental delivery & 14 (11.8) & $6(4.7)$ & $20(16.9)$ & \\
\hline
\end{tabular}

'For diabetes, urinary tract infections, hypertension and intrauterine growth restriction during pregnancy. ${ }^{2}$ Includes only the women who had the stress test.

${ }^{3}$ None of the women was delivered post-term ( $\geq 42$ weeks).

${ }^{4}$ Data were missing for 3 women in Group I and 2 women in Group III.

\section{Discussion}

Our results show that the mean duration of the first stage of labour in the obese/overweight group was significantly longer than that of the normal weight and thin groups. In addition, women in the thin group had a shorter first stage of labour than the normal weight group. Furthermore, the mean duration of the second stage of labour in obese/overweight group was longer than the normal weight and thin groups and again women in the thin group had a shorter second stage than the normal weight group. These results are similar to those obtained in other studies in the Islamic Republic of Iran (3) and in the United States of America $(5,6)$. However, an Australian study reported no relationship between the duration of the first, second and third stages of labour and BMI (7).

In our study, there was no significant difference between the obese/overweight and normal weight groups in the frequency of caesarean section compared with vaginal delivery. However, instrumental delivery was significantly more frequent in the obese/overweight group than the normal weight group; there was no significant difference between the thin and normal weight groups. This might be because of efforts to extend vaginal delivery and reduce caesarean sections. Therefore, the rate of instrumental delivery, such as vacuumassisted vaginal delivery, has increased to avoid unnecessary caesarean sections. Several studies show an increase in the rate of instrumental delivery in obese women, who in the past would have delivered by caesarean section. In addition, studies in the Islamic Republic of Iran and India have shown a high correlation between maternal obesity and caesarean section and instrumental delivery $(2-4,8-10)$.

In our study, the mean weight of neonates in both the obese/overweight and normal weight groups was greater 


\begin{tabular}{|c|c|c|c|c|}
\hline Variable & $\begin{array}{c}\text { Group I } \\
\text { BMI } \leq 19.8 \mathrm{~kg} / \mathrm{m}^{2}\end{array}$ & $\begin{array}{c}\text { Group II } \\
\text { BMI 19.9-24.9 } \\
\text { kg/m2 }\end{array}$ & $\begin{array}{c}\text { Group Ш } \\
\text { BMI } \geq 25 \mathrm{~kg} / \mathrm{m}^{2}\end{array}$ & $P$-value ${ }^{1}$ \\
\hline & Mean (SD) & Mean (SD) & Mean (SD) & \\
\hline Duration of the first stage of labour & $196.8(113.1)$ & $231.7(99.4)$ & $267.1(112.6)$ & $<0.001$ \\
\hline Duration of the second stage of labour & $4(35.6)$ & $51.8(34.4)$ & $65.7(37.7)$ & $<0.001$ \\
\hline Newborn weight (g) & $3140.1(385.3)$ & $3246.8(449.01)$ & $3332.4(528.6)$ & 0.003 \\
\hline
\end{tabular}

'ANOVA.

$S D=$ standard deviation.

\begin{tabular}{|c|c|c|c|c|}
\hline \multirow[t]{2}{*}{ Variable } & \multicolumn{2}{|c|}{ Gp I vs Gp II } & \multicolumn{2}{|c|}{ Gp III vs Gp II } \\
\hline & OR $(95 \% \mathrm{Cl})$ & $P$-value & OR $(95 \% \mathrm{CI})$ & $P$-value \\
\hline C-section vs normal vaginal & $0.15(0.03-0.68)$ & 0.013 & $1.9(0.94-4.16)$ & 0.072 \\
\hline Instrumental vs normal vaginal & $2.4(0.901-6.61)$ & 0.078 & $4.6(1.77-12.03)$ & 0.002 \\
\hline Induction & $0.43(0.26-0.73)$ & 0.002 & $1.4(0.82-2.45)$ & 0.2 \\
\hline Augmentation & $0.5(0.16-1.54)$ & 0.23 & $1.6(0.60-4.69$ & 0.32 \\
\hline Gestational hypertension & $0.01(0.01-0.23)$ & 0.028 & $0.96(0.34-2.44)$ & 0.92 \\
\hline Nonreactive nonstress test & $1.66(0.41-6.69)$ & 0.47 & $5.7(1.40-17.06)$ & 0.009 \\
\hline
\end{tabular}

than the thin group, however, there was no significant difference between the obese/overweight group and normal weight group. Other studies have shown a significant association between increased neonatal birth weight and maternal obesity $(2,4,8-12)$.

To conclude, our study showed several pregnancy complications related to higher maternal BMI: increased likelihood of longer labour, instrumental delivery and larger babies. Women of childbearing age should be encouraged to maintain a normal BMI. In addition, for both underweight and overweigh/ obese women, pre-pregnancy counselling, health programmes and appropriate multidisciplinary management should be offered. We categorized the women into 3 groups; in order to determine the effect of BMI on pregnancy outcomes more clearly, studies with 4 groups (in which the overweight and obese groups are separated) and larger sample sizes are recommended.

\section{Funding: None.}

Competing interests: None declared.

\section{References}

1. Li N, Liu E, Guo J, Pan L, Li B, Wang P, et al. Maternal prepregnancy body mass index and gestational weight gain on pregnancy outcomes. PLoS One. 2013 Dec 20;8(12):e82310.

2. Moghadami N, Aminikhah B, Davari Tanha F. The effect of maternal body mass index on spontaneous versus induced preterm birth: a prospective study. Tehran Univ Med J. 2009 Jun;67(3):221-5.

3. Dadras A, Ahmadi Z, Danesh-Kojuri M, Hosseini F. Relationship between pre-pregnancy body mass index and childbirth outcomes in primiparous women. Iran Journal of Nursing. 2010;22(62):56-64.

4. Sahu MT, Agarwal A, Das V, Pandey A. Impact of maternal body mass index on obstetric outcome. J Obstet Gynaecol Res. 2007 October;33(5):655-9.

5. Kabiru W, Raynor D. Obstetric outcomes associated with increase in BMI category during pregnancy. Am J Obstet Gynecol. 2004;191:928-32.

6. Baksh L, Bloebaum L, Barley J, Streeter N, Carapezza D, Crowley $\mathrm{P}$, et al. Maternal pre-pregnancy body mass index and pregnancy outcomes in Utah. A pregnancy risk assessment monitoring system report; 2005. Salt Lake City (UT): Reproductive Health Program, Utah Department of Health; 2005 (http:// digitallibrary.utah.gov/awweb/awarchive?item=11646, accessed 6June 2017).

7. Doherty DA, Magann EF, Francis JC, Newnham JP. Pre-pregnancy body mass index and pregnancy outcomes. Int J Gynaecol Obstet. 2006;95:242-7.

8. Pakniat H, Mohammadi F, Ranjkesh F. The impact of body mass index on pregnancy outcome. J Midwifery Reprod Health. 2015;3(2):361-7.

9. Najafi SA. Nomali M, Goudarzi Z, Maslahati A, Mobasheri E. Relationship between body mass index of third trimester of pregnancy and type of delivery. Tehran Univ Med J. 2015 March;72(12):831-7.

10. Behrashi M, Nasr Esfahani T, Behnamfar F, Nikzad H, Mousavi G. Maternal body mass index and complications of pregnancy and labor. Feyz (Journal of Kashan University of Medical Sciences). 2000;4(2):18-27.

11. Baeten JM, Bukusi EA, Lambe M. Pregnancy complications and outcomes among overweight and obese nulliparous women. Am J Public Health. 2001 March;91(3):436-40.

12. Nohr EA, Vaeth M, Baker JL, Sørensen TIA, Olsen J, Rasmussen KM. Combined associations of prepregnancy body mass index and gestational weight gain with the outcome of pregnancy. Am J Clin Nutr. 2008;87:1750-9. 